DOI: $10.36910 / 6775-2524-0560-2019-36-21$

УДК 681.125

О.М. Слабик аспірант,Ф.Д Матіко д. т. н. доцент., Л.В. Лесовой д. т. н. доцент

Національний університет «Львівська політехніка»

\title{
АЛГОРИТМ ВИЗНАЧЕННЯ КІЛЬКОСТІ ТЕПЛОВОЇ ЕНЕРГІЇ ДЛЯ СИСТЕМ ІЗ ЗАСТОСУВАННЯМ СТАНДАРТНИХ ЗВУЖУВАЛЬНИХ ПРИСТРОЇВ
}

Слабик О. М., Матіко Ф. Д., Лесовой Л. В. Алгоритм визначення кількості теплової енергії для систем із застосуванням стандартних звужувальних пристроїв. В статті представлено результати аналізу існуючих структур систем вимірювання кількості теплової енергії та рівнянь обчислення кількості теплової енергії, які застосовують у цих системах. Авторами виділено комплекс для обчислення інтегральної кількості енергії між двома точками системи теплопостачання, який $\epsilon$ складовою кожного з рівнянь, що застосовані у системах вимірювання кількості ТЕ. Розроблено алгоритм автоматизованого розрахунку кількості теплової енергії для систем із застосуванням стандартних звужувальних пристроїв, який реалізує повну математичну модель витратоміра змінного перепаду тиску. енергії.

Ключові слова: кількість теплової енергії, витрата теплоносія, алгоритм розрахунку, системи обліку теплової

Слабык О. М., Матико Ф. Д., Лесовой Л. В. Алгоритм определения количества тепловой энергии для систем с применением стандартных сужающих устройств. В статье представлены результаты анализа существующих структур систем измерения количества тепловой энергии и уравнений вычисления количества тепловой энергии, применяемые в этих системах. Авторами выделено комплекс для вычисления интегральной количества энергии между двумя точками системы теплоснабжения, который является составной частью каждого из уравнений, применены в системах измерения количества TE. Разработан алгоритм автоматизированного расчета количества тепловой энергии для систем с применением стандартных сужающих устройств, который реализует полную математическую модель расходомера переменного перепада давления.

Ключевые слова: количество тепловой энергии, расход теплоносителя, алгоритм расчета, системы учета тепловой энергии.

Slabyk O.M., Matiko F.D., Lesovoy L.V. Algorithm for determining the thermal energy amount for systems using standard pressure differential devices. The paper presents an analysis of the existing structures of thermal energy metering systems and the equations for calculating thermal energy amount used in these systems. The authors defined a complex for calculating the integral amount of energy between two points of heating system. This complex is a part of each equation used for the thermal energy metering systems. The algorithm is developed for automated calculating the thermal energy amount for systems based on standard pressure differential devices. It implements a complete mathematical model of a differential pressure flowmeter.

Keywords: thermal energy amount, heat carrier flowrate, calculating algorithm, thermal energy metering systems.

Постановка проблеми та аналіз останніх досліджень. Як відомо, структура системи обліку теплової енергії, а також рівняння визначення кількості теплової енергії залежать від схеми теплопостачання [1]. За результатами проведеного аналізу існуючих систем теплопостачання, стану обліку кількості теплової енергії та нормативного забезпечення систем обліку теплової енергії [2-5] сформовано таку класифікацію систем теплопостачання:

- за потужністю джерела теплової енергії: централізовані; децентралізовані; автономні;

- за видом теплоносія: водяні; парові;

- за способом приєднання системи опалення до системи: залежні; незалежні;

- за способом приєднання системи гарячого водопостачання до системи теплопостачання: закриті; відкриті;

- за кількістю трубопроводів для перенесення теплоносія: однотрубні; двотрубні; багатотрубні.

Розрахунок кількості теплової енергії виконують згідно «Правил обліку, відпуску і споживання теплової енергії» [3] та ДСТУ EN 1434-12006 Теплолічильники [5], які визначають основні технічні, організаційні і процедурні вимоги до здійснення обліку теплової енергії та теплоносія на джерелах теплопостачання та у споживачів теплової енергії. Проте зазначені документи не містять методики для розрахунку кількості теплової енергії в системах обліку з витратомірами змінного перепаду тиску.

Мета даної роботи: розроблення алгоритму визначення кількості теплової енергії із застосуванням стандартних звужувальних пристроїв на основі проведеного аналізу існуючих методик розрахунку кількості теплової енергії.

Враховуючи вище наведене проаналізуємо детальніше облік теплової енергії для поширених схем теплопостачання (таблиця 1).

Виклад основного матеріалу й обгрунтування отриманих результатів. Для закритих систем теплопостачання, при відсутності трубопроводу підживлення, для визначення кількості теплової 
енергії $(W)$ застосовують рівняння (1) або (2). Якщо ж підживлювальний трубопровід наявний, то застосовують рівняння (3), (4).

Такі рівняння застосовують у випадку, коли відсутній відбір теплоносія із системи, тобто $Q_{l}=Q_{2}$ [6]. За погодженням з енергопостачальною організацією один із витратомірів на подавальному або зворотному трубопроводах в закритій системі може бути відсутнім [6], незалежно від наявності чи відсутності в системі теплопостачання трубопроводу підживлення. В такому випадку для визначення кількості теплової енергії застосовують рівняння з переліку (1) - (4), відповідно до вимірюваних значень витрати.

Для визначення кількості теплової енергії у відкритих системах застосовують рівняння (5) [3]. Для реалізації цього рівняння необхідно вимірювати витрату теплоносія у подавальному трубопроводі $Q_{1}$, витрату теплоносія у зворотному трубопроводі $Q_{2}$, параметри теплоносія $\left(T_{1}, P_{1}, T_{2}\right.$, $\left.P_{2}\right)$ у подавальному та зворотному трубопроводах та параметри холодної води $\left(T_{\text {хв }}, P_{\text {хв}}\right)$.

На джерелі кількість теплової енергії, відпущеної по кожному виводу теплової мережі, обчислюють згідно наступних формул:

- (6) - за наявності витратоміра на подавальному трубопроводі;

- $\quad$ (7) - за наявності витратоміра на зворотному трубопроводі;

- (8) - за наявності різної кількості подавальних і зворотних трубопроводів та застосуванні підживлення від різних джерел.

Таблиця 1. Рівняння розрахунку кількості теплової енергії для поширених схем теплопостачання

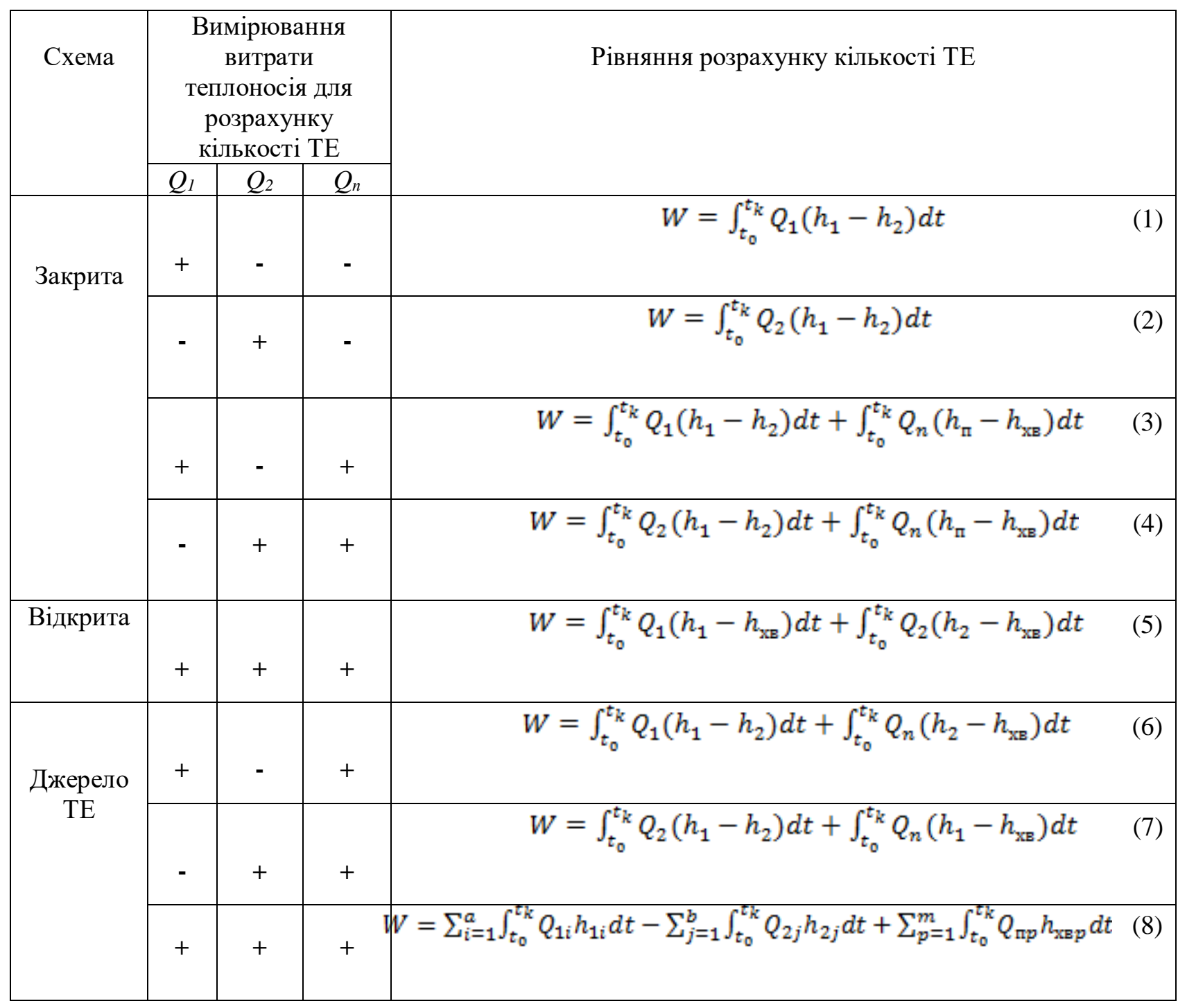


Як видно з таблиці 1, рівняння для обчислення кількості теплової енергії містять складові, які є результатом інтегрування добутку витрати теплоносія на різницю ентальпій потоку теплоносія у різних точках схеми теплопостачання. Отже, основою алгоритму обчислення кількості теплової енергії для будь-якої структури системи вимірювання ії витрати та кількості $є$ алгоритм обчислення інтегральної кількості енергії між двома точками системи теплопостачання, який реалізує рівняння:

$$
W=\int_{t_{0}}^{t_{k}} q_{w} d t=\int_{t_{0}}^{t_{k}} Q_{m}\left(h_{1}-h_{2}\right) d t
$$

де $q_{w}$ - потік теплової енергії $Q_{m}$ - масова витрата теплоносія, $Q_{l}=Q_{2}=Q_{m} ; h_{1}$ - питома ентальпія теплоносія в подавальному трубопроводі; $h_{2}$ - питома ентальпія теплоносія в зворотному трубопроводі; $t_{0}, t_{k}$ - час початку та кінця вимірювання.

Отже, згідно рівняння (9) для точного вимірювання кількості теплової енергії, яка переноситься потоком теплоносія, необхідно визначати витрату теплоносія $Q_{m}$, ентальпію теплоносія в подавальному трубопроводі $h_{1}=f\left(T_{\text {п }}, P_{\text {п }}\right)$ та ентальпію теплоносія в зворотному трубопроводі $h_{2}=$ $f\left(T_{3 в}, P_{\text {зв}}\right)$. Тому до складу системи вимірювання кількості теплової енергії повинен входити витратомір, вимірювальні перетворювачі тиску та температури теплоносія у подавальному трубопроводі $\left(T_{п}, P_{\text {п }}\right)$, вимірювальні перетворювачі тиску та температури теплоносія у зворотному трубопроводі ( $\left.T_{\text {зв}, ~} P_{\text {зв }}\right)$.

У багатьох системах обліку теплової енергії для вимірювання витрати теплоносія застосовують витратоміри змінного перепаду тиску зі стандартними звужувальними пристроями. Такі витратоміри реалізують рівняння [7]:

$$
Q_{m}=0,25 \pi d_{20}^{2} K_{c y}^{2} C E K_{\text {mI }} K_{\text {m }} \varepsilon(2 \Delta p \rho)^{0,5},
$$

де $d_{20}$ - діаметр отвору ЗП за температури $20^{\circ} \mathrm{C} ; K_{\text {су }}$ - коефіцієнт, який враховує зміну діаметра отвору ЗП, спричинену відхилами температури середовища від $20^{\circ} \mathrm{C} ; C$ - коефіцієнт витікання; $E$ коефіцієнт швидкості входження; $K_{\text {ш }}-$ поправковий коефіцієнт, який враховує шорсткість внутрішньої поверхні вимірювального трубопроводу (ВТ); $K_{\text {п }}$ - поправковий коефіцієнт, який враховує притуплення вхідного канта діафрагми; $\varepsilon$ - коефіцієнт розширення; $\Delta p$ - перепад тиску на ЗП; $\rho$ - густина середовища.

Нами розроблено алгоритм (див. рисунок 2) розрахунку потоку теплової енергії $q_{W}$ для системи, що реалізує рівняння (9) та у якій застосовано витратомір змінного перепаду тиску. У цьому алгоритмі реалізовано повну математичну модель витратоміра, зокрема, реалізовано ітераційний алгоритм розрахунку витрати теплоносія (див. рис.2).

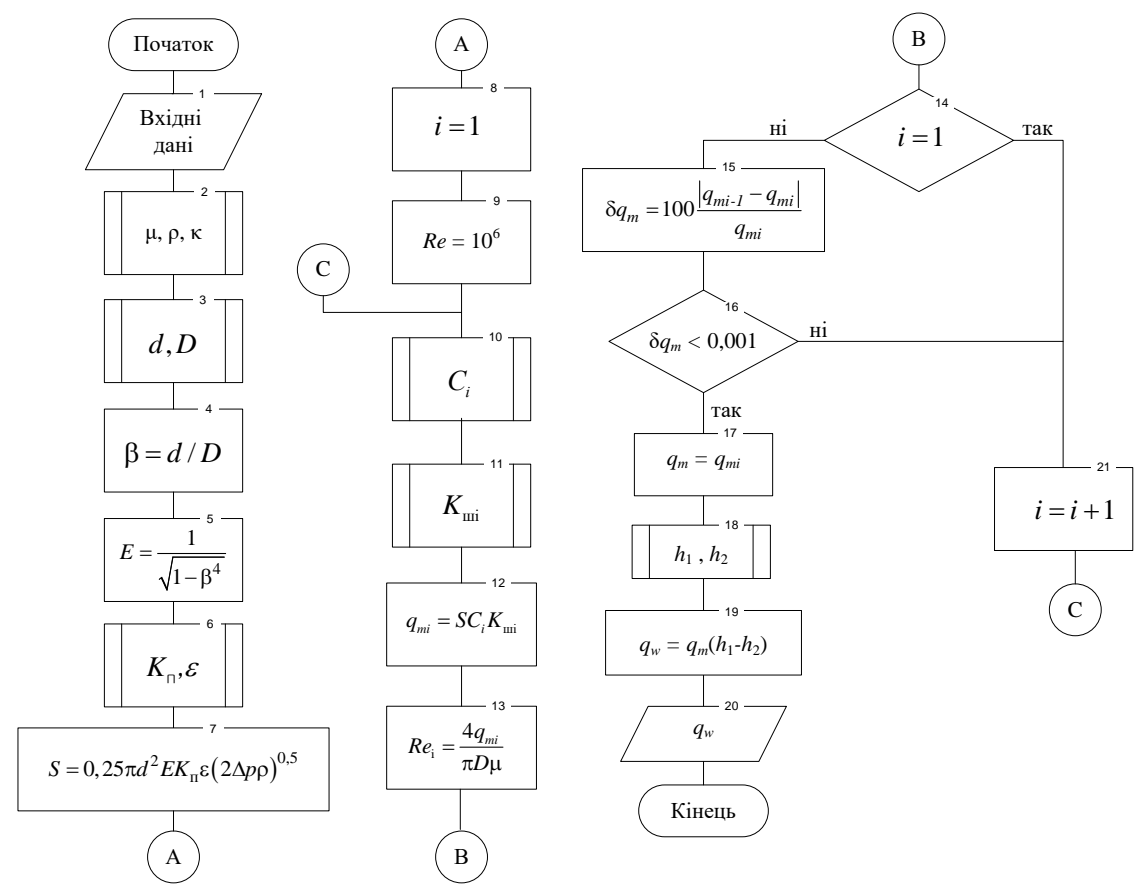

Рисунок 2. Блок-схема алгоритму розрахунку потоку теплової енергії за одиницю часу для системи на основі стандартного звужувального пристрою

( С Слабик О. М., Матіко Ф. Д., Лесовой Л. В. 
В тілі ітераційного процесу виконується розрахунок тих коефіцієнтів та параметрів рівняння витрати (10), які залежать від витрати середовища, зокрема: коефіцієнта витікання $C$, поправкового

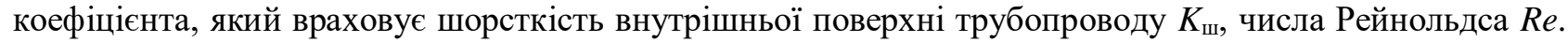
Розрахунок параметрів середовища: динамічної в'язкості $\mu$, густини $\rho$, показника адіабати к (тільки для газоподібного середовища) [7] та ентальпій $h_{1}, h_{2}$ згідно [8] доцільно виконувати поза ітераційним процесом. Наприкінці тіла ітераційного процесу обчислюється відносне відхилення $\delta q_{m}$ поточного значення масової витрати середовища $q_{m i}$ від попереднього $q_{m i-1}$. Вихід 3 циклу здійснюється за умовою порівняння відносного відхилення витрати $\delta q_{m}$ із значенням допустимої похибки розрахунку витрати. Як видно з рис.2, допустиме значення відносної похибки обчислення витрати прийнято рівним $0,001 \%$. Результатом виконання цього алгоритму є значення потоку теплової енергії за одиницю часу $q_{w}$.

Для обчислення кількості теплової енергії $W$, що спожита за певний інтервал часу, слід виконати інтегрування потоку теплової енергії за одиницю часу $q_{w}$. Оскільки в сучасних мікропроцесорних обчислювачах кількості теплової енергії період опитування вимірювальних перетворювачів (період квантування в часі) а також тривалість циклу розрахунку потоку теплової енергії $q_{w} \in$ достатньо малими, то для інтегрування застосовують прості методи, зокрема метод прямокутників. Цей метод інтегрування реалізовано за допомогою алгоритму, блок-схема якого зображена на рисунку 3. Інтегрування виконується на інтервалі часу від $t_{0}$ до $t_{k} 3$ кроком $\Delta t$. Алгоритм передбачає введення значень параметрів теплоносія в точці 1 системи теплопостачання (прямий трубопровід), а також в точці 2 (зворотний трубопровід) з кроком $\Delta t$ (див. блок 3 на рис.3). Таке введення виконується шляхом опитування вимірювальних перетворювачів параметрів теплоносія. На основі введених значень параметрів теплоносія в тілі ітераційного процесу виконується обчислення масової витрати за алгоритмом, блок-схема якого представлена на рис.2 (блок 4), ентальпії теплоносія в точці 1 (блок 5) та ентальпії теплоносія в точці 2 (блок 6) згідно 3 [8]. Розрахунок кількості теплової енергії між двома точками системи теплопостачання у певний момент часу здійснюється за формулою (9), (блок 7).

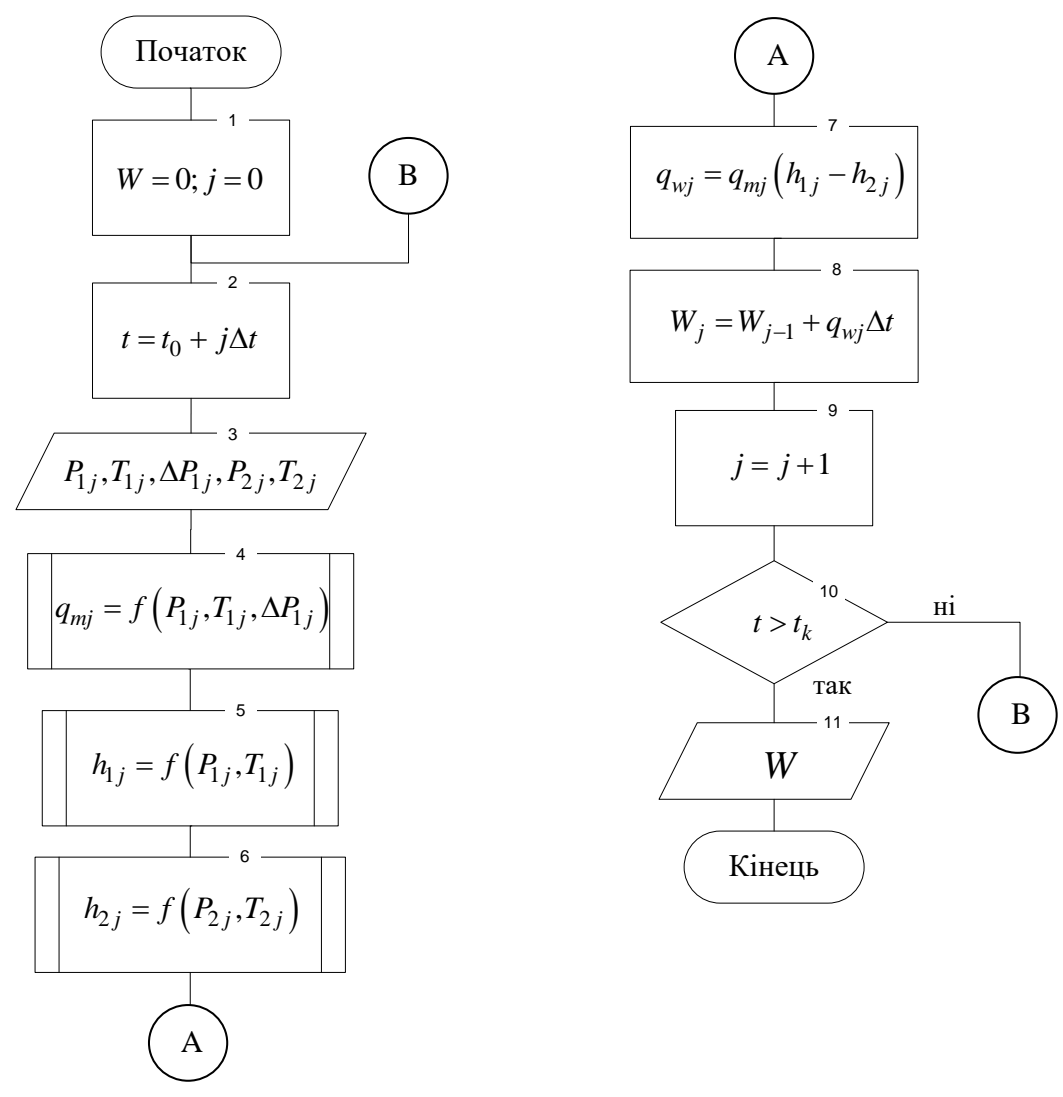

Рисунок 3. Блок-схема алгоритму обчислення кількості теплової енергії 
Наприкінці ітераційного процесу за методом прямокутників [9] обчислюється значення інтегральної кількості теплової енергії, використаної за певний інтервал часу (блок 8). Вихід з циклу здійснюється за умовою порівняння поточного значення часу $t$ із значенням часу завершення розрахунку $t_{k}$ (блок 10). Результатом виконання цього алгоритму є значення кількості теплової енергії використаної за визначений інтервал часу $W$ (блок 11). Межі інтервалу обчислення кількості теплової енергії $t_{0}$ та $t_{k}$ можуть бути визначені межі контрактного інтервалу визначення кількості теплової енергії (час початку контрактної доби, час завершення контрактної доби) .

Запропонований алгоритм планується ввести до системи автоматизованого розрахунку кількості теплової енергії на основі витратомірів змінного перепаду тиску, яку розробляють автори. Також цей алгоритм пропонується до застосування у обчислювачах теплової енергії, які $\epsilon$ обов'язковим елементом теплових лічильників, що повинні бути встановлені у споживачів, приєднаних до системи централізованого теплопостачання [10] та на джерелах теплової енергії.

Висновки та перспективи подалышого дослідження. В статті представлено результати аналізу поширених структур систем вимірювання кількості теплової енергії та рівнянь обчислення кількості теплової енергії, які застосовують у цих системах. Авторами розроблено алгоритм автоматизованого розрахунку кількості теплової енергії для систем із застосуванням стандартних звужувальних пристроїв, який реалізує повну математичну модель витратоміра змінного перепаду тиску. Застосування розробленого алгоритму дає можливість підвищити точність вимірювання кількості теплової енергії.

\section{Список бібліографічних посилань}

1. Matiko F. D. Аналіз нормативного забезпечення систем вимірювання кількості теплової енергії. Науковий вісник НЛТУ України. 2018. № 28(3). 105-110.

2. Інженерне обладнання будинків і споруд. Зовнішні мережі та споруди. Теплові мережі. ДБН В.2.5-39:2008. К. : Мінрегіонбуд України, 2009. 56 с.

3. Правила обліку, відпуску і споживання теплової енергії. К. : Міністерство з питань житлово-комунального господарства України, 2009. 96 с. (Проект)

4. Методика осуществления коммерческого учета тепловой энергии, теплоносителя. М. : Министерство строительства и жилищно-коммунального хозяйства РФ, 2014 г. 50 с.

5. Теплолічильники. Частина 1. Загальні вимоги (EN 1434-1:1997, IDT) ДСТУ EN 1434-12006. [Чинний від 2007-10-01]. К. : Держспоживстандарт України, 2007. 138 с.

6. Автоматизированная система учета энергоресурсов: тепла, воды, газа и электроэнергии АСКУЭ «СПЕКТР» [Електронний ресурс] / Суглоб Михаил Петрович. Режим доступу до ресурсу: http://www.askue-spektr.ru/

7. ДСТУ ГОСТ 8.586.5:2009 Метрологія. Вимірювання витрати та кількості рідини й газу із застосуванням стандартних звужувальних пристроїв. Частина 5. Методика виконання вимірювань [Текст]. [Чинний від 01.04.2010]. К.: Держстандарт України, 2010. 198 с.

8. МИ 2412-97. ГСИ. Водяные системы теплоснабжения. Уравнения измерений тепловой энергии и количества теплоносителя [Текст]. Введена в действие с 01.09.1997. М.: ВНИИМС, 1997. - 40 с.

9. Опалення, вентиляція та кондиціонування ДБН В.2.5-67:2013. К. : Міністерство регіонального розвитку, будівництва та житлово-комунального господарства України, 2013. 147 с.

10. Щедріна О.I. Алгоритмізація та програмування процедур обробки інформації: Навч. посібник / Щедріна О.І. К.: KHEУ, 2001. 240c. 